\title{
0303 CONVERGENCE BETWEEN FATHER AND YOUTH REPORTS OF HIGH RISK SAFETY BEHAVIOURS ON THE FARM
}

Z Stoneman*, H Jinnah-Ghelani* Correspondence: IHDD/University of Georgia, 850 College Station Rd., Athens, GA, 30607, USA

\subsection{6/ip.2010.029215.303}

Parents assign dangerous farm work to children. Injury and death rates in the Southern USA are high with $40 \%$ of US farm youth fatalities (Adekoya and Pratt, 2001) and 30\% of youth injuries (NASS, 2001). It is important to understand the degree of similarity in data obtained from youth and their fathers about high-risk behaviours of youth. This study examined reports of 86 farm youth and their fathers about the youths engagement in 25 high risk behaviours. Youth were aged 10-16; when families had more than one child, the youth who was most involved in farming participated in the study. There were significant differences between father and youth reports; fathers markedly underestimated risky behaviours engaged in by youth. For example, only $1 \%$ of fathers believed that their child had engaged in the extremely dangerous behaviour of stepping over a running PTO; $11 \%$ of youth had done this. Only $8 \%$ of fathers believed that the youth had operated a tractor on a steep slope; $66 \%$ of youth had done so; $21 \%$ of fathers believed youth had operated a tractor near a ditch or creek, $86 \%$ of youth had done so; $33 \%$ of fathers believed youth had operated a tractor at night, $69 \%$ of youth had done so; $59 \%$ of fathers believed youth had operated a tractor on a public road, $90 \%$ of youth had done so. Youth reported operating tractors at much younger ages than did fathers. Methodological implications of findings are discussed, as are recommendations for safety interventions. 